\title{
Endoscopic Papillary Large Balloon Dilation: Guidelines for Pursuing Zero Mortality
}

\author{
Dong Ki Lee and Jung Woo Han \\ Department of Internal Medicine, Gangnam Severance Hospital, Yonsei University College of Medicine, Seoul, Korea
}

\begin{abstract}
Since endoscopic papillary large balloon dilation (EPLBD) is used to treat benign disease and as a substitute for conventional methods, such as endoscopic sphincterotomy plus endoscopic mechanical lithotripsy, we should aim for zero mortality. This review defines EPLBD and suggests guidelines for its use based on a review of published articles and our large-scale multicenter retrospective review.
\end{abstract}

Key Words: Endoscopic papillary large balloon dilation; Endoscopic sphincterotomy; Mechanical lithotripsy

\section{INTRODUCTION}

Endoscopic papillary large balloon dilation (EPLBD) can be used as a treatment of removing the difficult common bile duct (CBD) stone. Yet, the appropriate EPLBD guidelines have not been satisfied. Thus, we are suggesting the guidelines as to strict indication and proper methology of EPLBD.

\section{WHY EPLBD?}

Endoscopic mechanical lithotripsy (EML) can be used when stone removal is impossible with a full endoscopic sphincterotomy (EST) due to larger size of the stone compared with that of the incised papillary orifice. Although the success rate of EML is high, it has several disadvantages such as longer procedure time, possible injury to the EST site or distal bile duct due to the use of accessories, and the effect of the stone-capturing basket. A full incision of the papillary sphincter causes complications such as bleeding, perforation, and pancreatitis in $5 \%$ to $10 \%$ of cases. By contrast, EPLBD requires only a small EST or none at all, rather than a full incision. EPLBD is

Received: July 17, 2012 Revised: July 20, 2012

Accepted: July 20, 2012

Correspondence: Dong Ki Lee

Department of Internal Medicine, Gangnam Severance Hospital, Yonsei University College of Medicine, 211 Eonju-ro, Gangnam-gu, Seoul 135-720, Korea Tel: +82-2-2019-3214, Fax: +82-2-3463-3882, E-mail: dklee@yuhs.ac

(c) This is an Open Access article distributed under the terms of the Creative Commons Attribution Non-Commercial License (http://creativecommons.org/ licenses/by-nc/3.0) which permits unrestricted non-commercial use, distribution, and reproduction in any medium, provided the original work is properly cited. believed to enable avoiding the complications of the full EST.

Ersoz et al. ${ }^{1}$ first introduced this method in 2003, but it did not attract attention at that time. Surgeons seem to be concerned about major adverse events (AEs), such as severe pancreatitis and bile duct perforation after large balloon inflation. However, recent data suggest that EPLBD is an effective procedure which does not cause serious AEs if performed under strict guidelines using proper techniques.

The main purpose of this procedure is to avoid or reduce the use of EML for removal of large and difficult CBD stones; it minimizes the complications associated with EML, shortens the procedure time, and consequently reduces radiation exposure. Additional aim of this method is to reduce the complication rate by avoiding full incision EST. ${ }^{2}$

After inflation of the large balloon, the papilla orifice forms a large, round hole (Fig. 1). In many cases, the hole is large enough to observe the mucosa of the distal bile duct. This indicates that the distal bile duct and papillary orifice are dilated as much as the CBD. Ultimately, the bile duct assumes a uniform cylindrical shape, facilitating stone removal.

\section{WHAT ARE THE INDICATIONS FOR EPLBD?}

Keeping within the strict indications for EPLBD is crucial to avoid serious AEs. Patients targeted for this method are those who already have a dilated CBD due to a large stone. Consequently, the tissue of the ampulla and distal CBD are ready to be dilated and further gradual stretching of the tissue will not 


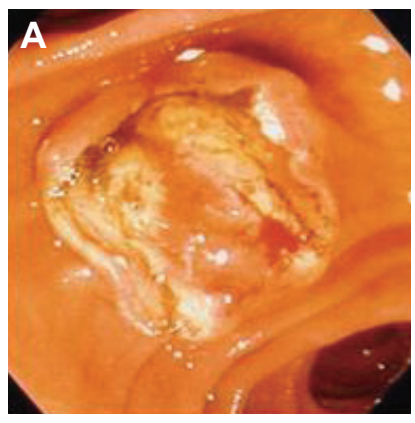

Tapered CBD
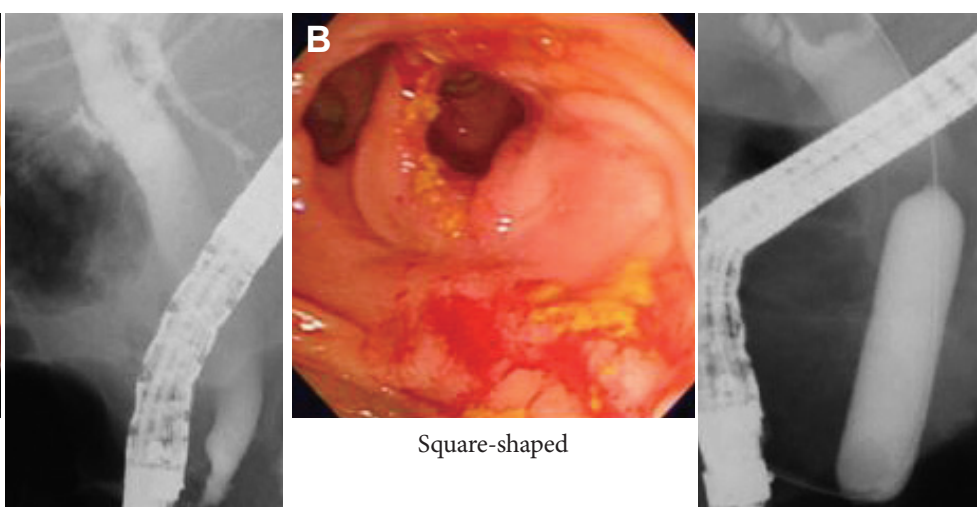

Fig. 1. (A) Distal common bile duct (CBD) shows a tapered end after full endoscopic sphincterotomy. (B) Large balloon inflation makes a square-shaped distal CBD and ampullary orifice for ease of stone passage.

Table 1. Methods and Outcomes of EPLBD

\begin{tabular}{|c|c|c|c|c|c|c|c|}
\hline Author & Year & $\begin{array}{c}\text { No. of } \\
\text { patients }\end{array}$ & $\begin{array}{l}\text { Preceding } \\
\text { incision }\end{array}$ & $\begin{array}{c}\text { Balloon } \\
\text { diameter, } \mathrm{mm}\end{array}$ & $\begin{array}{l}\text { Ballooning } \\
\text { time, sec }\end{array}$ & $\begin{array}{c}\text { Total stone removal } \\
\text { success rate, } \%\end{array}$ & $\begin{array}{l}\text { Use of EML } \\
\text { rate, } \%\end{array}$ \\
\hline Ersoz et al. ${ }^{1}$ & 2003 & 58 & Full & $12-20$ & $20-45$ & 100 & 6.9 \\
\hline Maydeo et al. ${ }^{3}$ & 2007 & 60 & Full & $12-15$ & 30 & 100 & 5 \\
\hline Minami et al. ${ }^{4}$ & 2007 & 88 & Mid & 20 & NA & 99 & 1 \\
\hline Heo et al. ${ }^{5 a)}$ & 2007 & 100 & Mid & $12-20$ & 60 & 97 & 8 \\
\hline Lee et al. ${ }^{6}$ & 2007 & 55 & Mid & $15-20$ & $30-60$ & 100 & 5.5 \\
\hline Attasaranya et al. ${ }^{7}$ & 2008 & 103 & Full & $\geq 12$ & NA & 95.1 & 27.2 \\
\hline Misra et al. ${ }^{8}$ & 2008 & 50 & Full & $15-20$ & $30-45$ & 100 & 10 \\
\hline Itoi et al. ${ }^{9 a)}$ & 2009 & 53 & Full & $15-20$ & $15-30$ & 100 & 5.6 \\
\hline Kurita et al..$^{10 b)}$ & 2010 & 24 & NA & $15-20$ & 30 & 95.8 & 4.2 \\
\hline Kim et al. ${ }^{11}$ & 2010 & 139 & Mid & $10-20$ & NA & 94.2 & 12.9 \\
\hline Kim et al. ${ }^{12 b)}$ & 2010 & 70 & NA & $12-18$ & 60 & 100 & 1.4 \\
\hline Kim et al. ${ }^{13 a)}$ & 2011 & 72 & Mid & $12-20$ & 30 & 97.2 & 8.3 \\
\hline Youn et al. ${ }^{14}$ & 2011 & 101 & Mid & $15-20$ & $30-60$ & 100 & 6.9 \\
\hline Stefanidis et al. ${ }^{15 a)}$ & 2011 & 45 & Full & $15-20$ & $10-12$ & 97.7 & 0 \\
\hline Chan et al. ${ }^{16 c)}$ & 2011 & 247 & No & $10-20$ & $120-360$ & 92.7 & 15.8 \\
\hline Poincloux et al. ${ }^{17}$ & 2012 & 62 & Mid & $15-20$ & $30-60$ & 98.3 & 4.7 \\
\hline Rebelo et al. ${ }^{18}$ & 2012 & 30 & Mid & $12-18$ & 60 & 16.6 & 20 \\
\hline Sakai et al..$^{19}$ & 2012 & 59 & Full & $12-20$ & NA & 100 & 13.6 \\
\hline $\begin{array}{l}\text { Our study } \\
\text { (unpublished article) }\end{array}$ & 2012 & 946 & Non, mid, full & $12-20$ & $30-180$ & 96.9 & 20.6 \\
\hline
\end{tabular}

EPLBD, endoscopic papillary large balloon dilatation; EML, endoscopic mechanical lithotripsy; NA, not available.

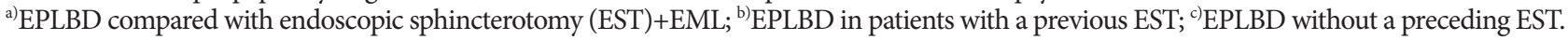

cause stress or sudden tearing of the ampullary roof. ${ }^{2}$ Patients with the CBD of less than the balloon size are not suitable for this procedure. For the same reason, patients with strictures of the distal CBD due to repeated cholangitis should be excluded considering the possibility of perforation. Unlike obvious strictures, however, occult or invisible strictures can be detected only during balloon inflation.

\section{AES}

\section{From previous reports}

There are many reports of the outcomes and adverse effects of EPLBD. Fortunately, most AEs are mild, and few serious AEs have been reported. Nevertheless, this does not mean that EPLBD is completely safe in patients with dilated CBD, considering the lack of large-scale multicenter clinical studies and possible reluctance of clinicians to report serious AEs. The 
Table 2. Complications of EPLBD

\begin{tabular}{|c|c|c|c|c|c|c|c|}
\hline Author & Total & Pancreatitis & Bleeding & Perforation & Cholangitis & Others & Mortality \\
\hline Ersoz et al. ${ }^{1}$ & 7 & 2 & 3 & 0 & 2 & 0 & 0 \\
\hline Maydeo et al. ${ }^{3}$ & 5 & 0 & 5 & 0 & 0 & 0 & 0 \\
\hline Minami et al. ${ }^{4}$ & 15 & 1 & 1 & 0 & 1 & $\begin{array}{l}\text { Injured bile duct, } 1 \text {; hypoxia, } 1 ; \\
\text { hypotension, } 10\end{array}$ & 0 \\
\hline Heo et al. ${ }^{5 a)}$ & 5 & 4 & 0 & 0 & 1 & 0 & 0 \\
\hline Lee et al. ${ }^{6}$ & 10 & 0 & 2 & 0 & 0 & Elevated amylase/lipase, 8 & 0 \\
\hline Attasaranya et al. ${ }^{7}$ & 5 & 0 & 2 & 1 & 0 & $\begin{array}{l}\text { Abdominal pain, } 1 \text {; } \\
\text { intramural dissection, } 1\end{array}$ & 0 \\
\hline Misra et al. ${ }^{8}$ & 7 & 4 & 3 & 0 & 0 & 0 & 0 \\
\hline Itoi et al. ${ }^{9 a)}$ & 2 & 1 & 0 & 0 & 1 & 0 & 0 \\
\hline Kurita et al. ${ }^{10 b)}$ & 1 & 0 & 0 & 0 & 0 & Aspiration pneumonia, 1 & 0 \\
\hline Kim et al. ${ }^{11}$ & 10 & 9 & 1 & 0 & 0 & 0 & 0 \\
\hline Kim et al. ${ }^{12 b)}$ & 1 & 1 & 0 & 0 & 0 & 0 & 0 \\
\hline Kim et al. ${ }^{13 a)}$ & 8 & 6 & 0 & 1 & 1 & 0 & 0 \\
\hline Youn et al. ${ }^{14}$ & 10 & 5 & 2 & 1 & 0 & Intramural dissection, 2 & 0 \\
\hline Stefanidis et al. ${ }^{15 a)}$ & 11 & 2 & 2 & 1 & 6 & 0 & 0 \\
\hline Chan et al. ${ }^{16 c)}$ & 3 & 2 & 0 & 0 & 1 & 0 & 0 \\
\hline Poincloux et al. ${ }^{17}$ & 18 & 2 & 14 & 0 & 0 & Sepsis, 2 & 0 \\
\hline Rebelo et al. ${ }^{18}$ & 13 & 1 & 1 & 0 & 0 & $\begin{array}{c}\text { Abdominal pain, } 3 ; \\
\text { elevated amylase/lipase, } 8\end{array}$ & 0 \\
\hline Sakai et al. ${ }^{19}$ & 4 & 0 & 1 & 1 & 1 & Pneumonia, 1 & 0 \\
\hline $\begin{array}{l}\text { Our study } \\
\text { (unpublished article) }\end{array}$ & 95 & 24 & 56 & 9 & 6 & NA & 4 \\
\hline
\end{tabular}

EPLBD, endoscopic papillary large balloon dilatation; NA, not available.

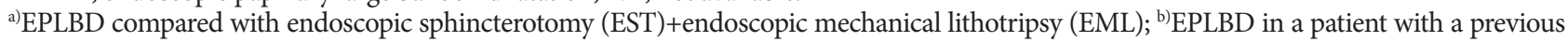
$\mathrm{EST} ;{ }^{\mathrm{c})} \mathrm{EPLBD}$ without a preceding EST.

outcomes and AEs of EPLBD are summarized in Tables $1,2 .^{1,3-19}$

During the initial trials of this procedure, the occurrence of pancreatitis was of much concern because a large balloon was used. In practice, however, no case of severe pancreatitis has been reported. ${ }^{15}$ One possible reason for this lack of pancreatitis occurrence is that the incision of the papillary orifice may shift the expansive force more toward the CBD than toward the pancreas orifice. In addition, the incidence and severity of pancreatitis were not related to the duration of ballooning. EPLBD without a preceding papillary incision did not cause severe pancreatitis. ${ }^{16}$ Therefore, ballooning itself may not be the culprit. Considering EPLBD, the cause of fatal pancreatitis during endoscopic papillary balloon dilation (EPBD) should be reconsidered. Instead of balloon compression of the pancreatic flow, edema or spasm caused by irritation of the pancreatic orifice while performing difficult selective cannulation and struggling to remove the stone may be the main determinants of severe pancreatitis during EPLBD and EPBD.

There is no need to worry about bleeding during partial EST. Even if a small amount of bleeding does occur, it will be controlled by the subsequent balloon inflation. The advantage of a small incision in comparison with a full EST is the reduced possibility of cutting a major vessel in the papillary roof. However, after the EPLBD, there is a possibility of delayed bleeding with a preceding large incision of the papilla. Delayed bleeding may occur if the procedure is terminated without confirming complete hemostasis when there is bleeding during the procedure, or if the balloon compresses the injured vessel for an insufficient time. EPLBD without a preceding small EST is feasible for patients with large bile duct stones who are at risk of bleeding. In practice, uremic patients and those with advanced liver cirrhosis with large CBD stones can be treated successfully with EPLBD without EST. Minimal oozing after balloon inflation can occur with microvascular rupture accompanied by stretching of the mucosa. However, this does not often cause significant bleeding similar to that caused by a vascular cutting injury after EST.

\section{Lessons from our multicenter study}

Is EPLBD always safe? EPLBD is already widely accepted in Western countries. We feel responsible for establishing guidelines regarding the indications for EPLBD and the tech- 
nique. Our main concern is to identify invisible strictures to avoid a fatal AE. To answer this question, we conducted a large retrospective multicenter study. We enrolled 946 consecutive patients with large CBD stones. The patients were divided into two groups: those with and without AEs. Of the 946 patients, only 95 (10\%) experienced AEs.

Among the patients who suffered AEs, most cases of bleeding and pancreatitis were mild to moderate, with the exception of one case of bleeding. By contrast, perforation was classified as moderate to severe. We experienced five severe cases in total, four of which were fatal: one from bleeding and three from perforations. Most of the AEs were classified as mild, while those classified as severe were mostly fatal.

In this study, perforation was the most serious AE of EPLBD. The multivariate analysis indicated that a distal CBD stricture was an independent predictor of perforation, and we suggest that the presence of a distal CBD stricture should be considered as an absolute contraindication to EPLBD. Looking more closely at the causes of mortality, over-inflation and rapid inflation in patients with an undetermined CBD stricture caused perforation. In two cases, a notch remained during dilation but the balloon was inflated further, which caused severe perforation. In one case, the balloon was dilated rapidly without checking for resistance, which caused perforation. Of the three patients with perforations, two died of septic shock and multi-organ failure and the other of cardiogenic shock. In one patient, the full EST and subsequent thrombocytopenia caused delayed massive bleeding. Therefore, from these experiences, we believe that the accompanying guidelines should be followed strictly.

\section{GUIDELINES FOR THE PROPER TECHNIQUE}

\section{How big of an incision is needed before applying the balloon?}

The advantage of EPLBD is that it avoids the complications

of full EST. Partial EST is preferred over full EST because it avoids large-vessel injury and perforation. Indeed, we experienced one death due to delayed massive bleeding after full EST. In general, any intra-procedure bleeding was controlled easily using balloon tamponade at the EST site. Delayed bleeding may still occur in such patients whose large vessel located at the proximal part of the papillary roof is injured and is controlled only transiently using balloon tamponade at the incision site. Partial EST itself did not increase the risk of bleeding compared to non-EST, which might be explained by decreased likelihood of severing a major vessel in the papillary roof.

Another advantage of partial EST is direct observation of the remaining intact papillary roof during gradual balloon inflation, which can help to avoid perforation.

Another option is EPLBD without a preceding EST. This can be used in patients with severe bleeding tendencies. An EPLBD study comparing groups with preceding partial EST and no EST should be performed to determine the efficacy and safety of EPLBD without EST.

\section{How does one detect invisible strictures?}

While visible strictures are easily detectable, our main concern is to identify invisible strictures, which are detectable only during the procedure. Any marked resistance during balloon inflation is an absolute contraindication for continued inflation (Fig. 2A). To determine whether there is an invisible stricture, the balloon should not be inflated beyond $75 \%$ of the manufacturer's recommended maximum inflation capacity if resistance continues (Fig. 2B). EPLBD led to death of one of our patients in whom no obvious distal CBD stricture was identified before balloon inflation and the balloon waist did not disappear after inflating the balloon to $75 \%$ of the maximum recommended pressure. Although 75\% was determined arbitrarily, more importantly, the remaining waist should not be inflated forcibly. In addition, the balloon should always be inflated gradually and never exceed the CBD diameter. When a tapered distal CBD or invisible stricture is identified, the op-
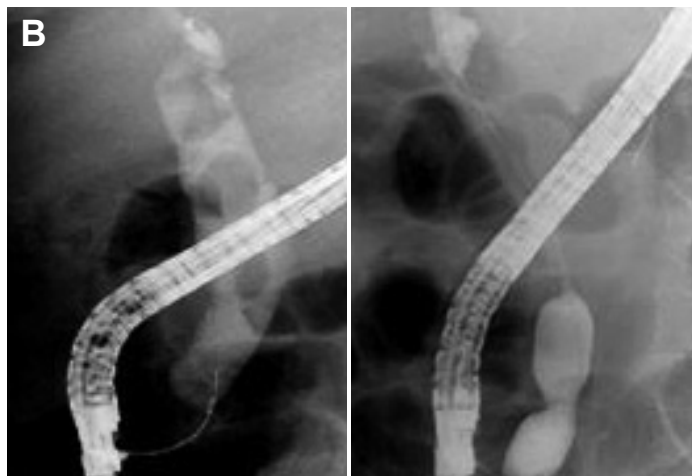

Fig. 2. (A) Strong resistance and distinct notch during balloon inflation; definite presence of strong stricture in the common bile duct (CBD). (B) Balloon notch remains after application of $75 \%$ of the maximal inflation pressure. Further forcible inflation of the balloon can cause distal CBD perforation. 
Table 3. Guidelines for Safe EPLBD

Strict indication

A patient with a dilated CBD without distal CBD strictures Proper method

1) Avoid a full EST before large balloon dilatation

2) Inflate the balloon gradually to recognize occult or undetermined strictures of the distal CBD shown by persistence of a waist during balloon dilation

3) Do not overinflate the balloon against resistance or a persistent balloon waist

- Stop inflation any time resistance indicates an obvious CBD stricture

- Stop inflation if the balloon waist persists before applying $75 \%$ of the recommended maximum inflation pressure

4) Do not inflate the balloon beyond the maximum diameter of the $\mathrm{CBD}$

5) Do not hesitate to switch to an alternative stone removal method such as mechanical basket lithotripsy and stenting

$\overline{\text { EPLBD, endoscopic papillary large balloon dilatation; CBD, com- }}$ mon bile duct; EST, endoscopic sphincterotomy.

erator should pay particular attention during balloon inflation to avoid fatal AEs due to a large perforation. The leakage of bile and pancreatic fluid through a large perforation and delay in the proper surgical intervention can lead to rapid deterioration in the patient.

\section{PROPOSED GUIDELINES FOR EPLBD}

Based on current knowledge, we propose the following: 1) EPLBD should be reserved for patients with dilated CBD and large stones, but avoided in patients with distal CBD strictures; 2) full EST should be avoided immediately before large balloon dilation to prevent perforation and bleeding; 3 ) the balloon should be inflated gradually to recognize narrowed distal CBD indicated by continued visibility of the balloon waist; 4) inflation should be discontinued when resistance is encountered in the presence of a persistent balloon waist (75\% rule); 5) the balloon should not be inflated beyond the maximum upstream diameter of the dilated CBD; and 6) the procedure should be converted to alternative stone removal or drainage method any time there is difficulty in removing the stone (Table 3) (unpublished article).

\section{FUTURE OF EPLBD}

EPLBD is already accepted worldwide. Nevertheless, as we know from our multi-center study, EPLBD is not free from fatal AEs such as perforation. However, if we keep within the strict indications and use proper techniques, EPLBD is safe and effective for removal of large, difficult CBD stones and can be an alternative to conventional full EST plus EML. However, more reliable guidelines for detection of invisible or undetermined distal CBD strictures are required.

At present, there are insufficient data regarding the effect of EPLBD on the ablation of sphincter function. The stone recurrence and cholangitis rates should be compared with conventional methods. Further data regarding EPLBD without EST are also needed.

\section{CONCLUSIONS}

By establishing strict indications and proper technique guidelines, we can achieve a zero mortality rate for EPLBD. Then EPLBD will be recognized as a superior alternative treatment for $\mathrm{CBD}$ stones.

\section{Conflicts of Interest}

The authors have no financial conflicts of interest.

\section{REFERENCES}

1. Ersoz G, Tekesin O, Ozutemiz AO, Gunsar F. Biliary sphincterotomy plus dilation with a large balloon for bile duct stones that are difficult to extract. Gastrointest Endosc 2003;57:156-159.

2. Lee DK, Lee BJ. EST, EPBD and EPLBD (cut, stretch, or both?). In: Niwa H, Tajiri H, Nakajima M, Yasuda K, eds. New Challenge in Gastrointestinal Endoscopy. Tokyo: Springer; 2008. p.385-397.

3. Maydeo A, Bhandari S. Balloon sphincteroplasty for removing difficult bile duct stones. Endoscopy 2007;39:958-961.

4. Minami A, Hirose S, Nomoto T, Hayakawa S. Small sphincterotomy combined with papillary dilation with large balloon permits retrieval of large stones without mechanical lithotripsy. World J Gastroenterol 2007; 13:2179-2182.

5. Heo JH, Kang DH, Jung HJ, et al. Endoscopic sphincterotomy plus large-balloon dilation versus endoscopic sphincterotomy for removal of bile-duct stones. Gastrointest Endosc 2007;66:720-726.

6. Lee DK, Lee BJ, Hwhang SJ, Baik YH, Lee SJ. Endoscopic papillary large balloon dilation after endoscopic sphincterotomy for treatment of large common bile duct stone. Dig Endosc 2007;19(Suppl 1):S52-S56.

7. Attasaranya S, Cheon YK, Vittal H, et al. Large-diameter biliary orifice balloon dilation to aid in endoscopic bile duct stone removal: a multicenter series. Gastrointest Endosc 2008;67:1046-1052.

8. Misra SP, Dwivedi M. Large-diameter balloon dilation after endoscopic sphincterotomy for removal of difficult bile duct stones. Endoscopy 2008;40:209-213.

9. Itoi T, Itokawa F, Sofuni A, et al. Endoscopic sphincterotomy combined with large balloon dilation can reduce the procedure time and fluoroscopy time for removal of large bile duct stones. Am J Gastroenterol 2009; 104:560-565.

10. Kurita A, Maguchi H, Takahashi K, Katanuma A, Osanai M. Large balloon dilation for the treatment of recurrent bile duct stones in patients with previous endoscopic sphincterotomy: preliminary results. Scand J Gastroenterol 2010;45:1242-1247.

11. Kim HW, Kang DH, Choi CW, et al. Limited endoscopic sphincterotomy plus large balloon dilation for choledocholithiasis with periampullary diverticula. World J Gastroenterol 2010;16:4335-4340.

12. Kim KO, Kim TN, Lee SH. Endoscopic papillary large balloon dilation for the treatment of recurrent bile duct stones in patients with prior sphincterotomy. J Gastroenterol 2010;45:1283-1288. 
13. Kim TH, Oh HJ, Lee JY, Sohn YW. Can a small endoscopic sphincterotomy plus a large-balloon dilation reduce the use of mechanical lithotripsy in patients with large bile duct stones? Surg Endosc 2011;25:33303337.

14. Youn YH, Lim HC, Jahng JH, et al. The increase in balloon size to over $15 \mathrm{~mm}$ does not affect the development of pancreatitis after endoscopic papillary large balloon dilatation for bile duct stone removal. Dig Dis Sci 2011;56:1572-1577.

15. Stefanidis G, Viazis N, Pleskow D, et al. Large balloon dilation vs. mechanical lithotripsy for the management of large bile duct stones: a prospective randomized study. Am J Gastroenterol 2011;106:278-285.

16. Chan HH, Lai KH, Lin CK, et al. Endoscopic papillary large balloon dilation alone without sphincterotomy for the treatment of large common bile duct stones. BMC Gastroenterol 2011;11:69.

17. Poincloux L, Rouquette O, Privat J, et al. Large-balloon dilation of the sphincter of Oddi after sphincterotomy or infundibulotomy to extract large calculi or multiple common bile duct stones without using mechanical lithotripsy. Scand J Gastroenterol. Epub 2012 Jan 10. DOI: http://dx.doi.org/10.3109/00365521.2011.647064.

18. Rebelo A, Ribeiro PM, Correia AP, Cotter J. Endoscopic papillary large balloon dilation after limited sphincterotomy for difficult biliary stones. World J Gastrointest Endosc 2012;4:180-184.

19. Sakai Y, Tsuyuguchi T, Sugiyama H, et al. Endoscopic Sphincterotomy Combined with Large Balloon Dilation for Removal of Large Bile Duct Stones. Hepatogastroenterology. Epub 2012 May 29. DOI: http://dx.doi. org/10.5754/hge12351. 